\title{
NOÇÕES DE SOLIDARIEDADE E RESPONSABILIDADE NO CAMPO DA COOPERAÇÃO INTERNACIONAL PARA A PROTEÇÃO DE REFUGIADOS
}

\author{
Paulo Ricardo Muller
}

\begin{abstract}
Tomando como fio condutor eventos relativos ao programa de Reassentamento Solidário de refugiados no Brasil, o artigo procura analisar como os princípios da solidariedade e da responsabilidade elaborados no âmbito de acordos internacionais são interpretados e ressignificados por atores situados em diferentes escalas de influência e participação na implementação das políticas de proteção e assistência a refugiados.
\end{abstract}

Palavras-chave: Solidariedade; Responsabilidade, Cooperação; Refugiados, Políticas. ${ }^{1}$

"Eles se tornaram responsáveis por mim quando me trouxeram para cá e precisam resolver esse problema".

A frase acima é atribuída ao refugiado palestino Farok Mansur que, em 2007, foi admitido no Brasil como refugiado internacional no âmbito do programa de Reassentamento Solidário, e problematiza a relação entre as retóricas da solidariedade e da responsabilidade no universo das políticas e programas de proteção de refugiados. Em 2008, quando concedeu o depoi-

\footnotetext{
* Professor de antropologia da Universidade Federal da Fronteira Sul - Campus Erechim (UFFS/ Erechim); Mestre em Antropologia Social pela Universidade Estadual de Campinas (UNICAMP); Doutorando em Antropologia Social na Universidade Federal do Rio Grande do Sul (UFRGS); Pesquisador do Núcleo de Antropologia e Cidadania (NACi) da UFRGS. E-mail: paulomuller@ gmail.com. Erechim - RS /Brasil.

${ }^{1}$ Este artigo foi originalmente elaborado como monografia de conclusão da disciplina Antropologia Econômica do Programa de Pós-Graduação em Antropologia Social da Universidade Federal do Rio Grande do Sul, ministrada pelos professores Ruben Oliven e Arlei Damo, aos quais agradeço pelos comentários e sugestões.
} 
mento, Mansur fazia parte de um grupo de nove refugiados palestinos que acampavam em frente à sede do Alto Comissariado das Nações Unidas para Refugiados (ACNUR) em Brasília como forma de reivindicar melhorias no serviço de assistência social prestado aos refugiados palestinos no Brasil, ou sua transferência para outro país. ${ }^{2} \mathrm{O}$ grupo de mais de cem palestinos reassentados no Brasil em 2007 vivia em instalações provisórias do ACNUR no campo de Ruweished, na Jordânia. O programa de Reassentamento Solidário, que viabilizou este processo, é uma medida projetada pelo Plano de Ação do México, acordo assinado em 2004 por vinte países latinoamericanos, que visava a "repartição do peso" político e econômico-demográfico que as migrações forçadas transfronteiriças vinham tendo, ao longo da década de 1990, inicialmente para os países vizinhos da Colômbia, mais tarde estendido para outras regiões do mundo.

A noção de solidariedade articulada pelos programas e políticas de proteção de refugiados nos permite analisar a construção do fenômeno das migrações forçadas e dos sujeitos refugiados a partir de diferentes escalas e campos semânticos de enunciação, perpassando pontos de vista locais, nacionais e transnacionais, bem como concepções jurídicas, políticas e humanitárias a respeito do tema. O objetivo deste artigo não é esgotar cada um destes pontos de vista, mas evidenciar a polissemia e os conflitos resultantes de diferentes interpretações e concepções da noção de solidariedade no âmbito das políticas de asilo contemporâneas. Embora sejam aplicados de formas diversas, de acordo com diferentes situações políticas e socioculturais locais e nacionais, os princípios da política de refúgio são construídos como um discurso global formalizado no âmbito de organizações que se constituem como centros de poder decisório e cujas resoluções e recomendações são divulgadas, traduzidas e incorporadas ao vocabulário de organizações sociais, da mídia e dos próprios sujeitos recipientes destas políticas. ${ }^{3} \mathrm{O}$ foco deste artigo se limita a esta dimensão das políticas de refúgio, tomando como contexto de observação dois eventos voltados para a discussão e divulgação do programa de Reassentamento Solidário nos quais se reuniram representantes de organizações estatais, da sociedade civil e das Nações Unidas atuantes na prestação de serviços e proteção a refugiados e solicitantes de asilo.

Buscarei analisar o processo de institucionalização das políticas de asilo por meio da difusão e naturalização do sentido de determinadas ideias, seguindo uma abordagem voltada para a compreensão dos valores e concepções em jogo nas políticas de desenvolvimento e cooperação

\footnotetext{
${ }^{2}$ Ver a reportagem "Refugiados palestinos protestam em Brasília para deixar o país".

${ }^{3}$ RIBEIRO, Gustavo Lins. Diversidade cultural enquanto discurso global, p. 217.
} 
internacional comunicadas através da linguagem de consultorias e avaliações de situações de crise política e humanitária. O estudo de uma política por meio de suas categorias ou palavras-chave permite construir observações etnográficas a respeito das práticas institucionais a partir dos termos e categorias correntes nas redes sociais de representantes, funcionários, consultores e beneficiários que participam da política analisada. ${ }^{4}$ As observações apresentadas aqui foram feitas, assim, em contextos que se destinavam à própria instrução de funcionários e consultores do ACNUR e de organizações da sociedade civil a respeito da situação de refugiados e solicitantes de asilo em diferentes contextos.

Na primeira seção do artigo apresento uma breve revisão teórica da noção de solidariedade, seu papel heurístico na construção de interpretações socioantropológicas a respeito de fenômenos de troca e circulação de ideias e coisas, e de que modo esta noção é relevante para pensar as políticas de proteção internacional de refugiados. Na segunda seção, apresento os contextos nos quais pude observar a articulação das ideias de solidariedade vis-a-vis a noção de responsabilidade na afirmação de relações entre organizações e instituições atuantes no programa de Reassentamento Solidário no Brasil. Na terceira seção busco a compreensão de como a ideia de solidariedade é interpretada e traduzida por atores situados em diferentes contextos e escalas de participação no processo de reassentamento de refugiados. Por fim, sintetizo os entendimentos a respeito da lógica social da cooperação para a proteção internacional e algumas implicações de sua análise para a compreensão das situações particulares de refugiados e das noções de solidariedade e responsabilidade.

\section{Noções de solidariedade e a política internacional de proteção a refugiados}

A noção de solidariedade está presente no pensamento socioantropológico como indicadora de relações sociais mais ou menos coesas e/ou politicamente corretas. Utilizada como um indicador de coesão social, sua análise de um ponto de vista sociológico remonta à tipologia de Durkheim $^{5}$, segundo a qual nas sociedades tradicionais ou precapitalistas as relações sociais seriam regidas por uma solidariedade mecânica, que agruparia indivíduos em esferas e práticas sociais coletivas e indiferenciadas entre si, enquanto nas sociedades complexas capitalistas as relações seriam

\footnotetext{
${ }^{4}$ APTHORPE, Raymond. Writing development policy and policy analysis plain or clear: on language, genre and power, p. 11.

${ }^{5}$ DURKHEIM, Émile. Da divisão social do trabalho.
} 
regidas por uma solidariedade orgânica, que levaria ao agrupamento de indivíduos de acordo com suas funções específicas assumidas no processo de divisão social do trabalho.

Mauss $^{6}$ e Lévi-Strauss ${ }^{7}$ ampliaram o sentido da noção de solidariedade para além da relação entre indivíduo e sociedade. Ao analisar o princípio da reciprocidade como norma do sistema de trocas e circulação melanésio, Mauss apresenta as relações de troca não apenas como transações comerciais, mas também como meios de construção de uma socialidade melanésia a partir dos quais a solidariedade intragrupal passaria a ser aplicada também nas relações intergrupais. Assim, os produtos e serviços trocados não teriam seu valor regulado por sua utilidade ou raridade, mas por sua destinação acordada ritualmente nas ocasiões de troca. A dádiva, como tradução do valor moral acrescido ao valor transacional dos préstimos trocados, operaria simultaneamente como um contrato de direitos e deveres e como uma instância de resolução de conflitos, na medida em que a equivalência entre coisas trocadas deveria representar o reconhecimento social entre as partes. A partir da leitura da obra de Mauss, Lévi-Strauss sugeriu que, mais do que contratos entre partes discretas, as relações de troca expressariam noções parciais de uma totalidade representativa do conjunto das alianças intergrupais. Neste caso, a solidariedade entre grupos sociais distintos não seria gerada pelas ações de dar, receber ou retribuir, mas pela consubstancialidade entre as partes traduzida pela eficácia social das trocas e alianças. ${ }^{8}$

Releituras do Ensaio sobre a dádiva, de Mauss, sugerem haver, nas ciências sociais, uma sobre-ênfase na noção de dádiva como uma explicação de como se constituem culturalmente o mercado e o campo econômico a despeito das considerações igualmente relevantes a respeito da moral e do direito contidas na obra. ${ }^{9}$ Partindo da discussão a respeito da diferenciação entre estas esferas surgem abordagens que buscam evidenciar o quanto a racionalidade econômica é permeada por valores socialmente atribuídos a outras esferas, desnaturalizando fronteiras simbólicas entre o campo econômico e outros campos. ${ }^{10}$ Tais abordagens discutem a intercambialidade entre valores atribuídos a estas diferentes esferas quando mobilizados para

${ }^{6}$ MAUSS, Marcel. Sociologia e antropologia.

${ }^{7}$ LÉVI-STRAUSS, Claude. Introdução à obra de Marcel Mauss.

${ }^{8}$ Ibidem, p. 40.

${ }^{9}$ HART, Keith. Marcel Mauss: in Pursuit of the Whole. A Review Essay; GODELIER, Maurice. $O$ enigma do dom; SCHULTE-TENCKHOFF, Isabelle. Potlatch n'est qu'un mot; TAROT, Camille. L'économique et le social, ou l'utopie.

${ }^{10}$ CHANIAL, Phillipe. Generosité, réciprocité, pouvoir et violence: esquisse d'une grammaire des relations humaines en clé de don; CHAVAGNEUX, Christian. Une maîtrise politique de la mondialisation economique; ZELIZER, Viviana. Intimité et economie. 
construir interpretações e posicionamentos éticos em situações de conflito, divergência ou disputa.

A operacionalização desta perspectiva como projeto de sociedade por parte de redes de colaboração entre movimentos sociais em escala mundial constituiu um polo de enunciação de valores políticos contra-hegemônicos e de propostas de governança em contraposição aos mecanismos de regulação da economia política global vigentes nos regimes de cooperação e comércio baseados na dicotomia entre países desenvolvidos e subdesenvolvidos. ${ }^{11} \mathrm{~A}$ formação e difusão de circuitos transnacionais de troca e circulação alternativos aos mecanismos oficiais de comércio e imigração evidenciaram a emergência de novas frentes de expansão do capitalismo global por meio da incorporação de grupos até então considerados excluídos ou à margem dos mercados de bens e serviços organizados em sistemas mundiais não-hegemônicos. ${ }^{12}$ Valores e conceitos articulados pelos movimentos de contestação da ordem global passaram, assim, a compor discursos politicamente corretos ou socialmente responsáveis também de corporações privadas e instituições estatais e interestatais como uma forma de inserção de atores sociais identificados com estes valores nos regimes democráticos e no mercado de consumo.

O sistema de proteção internacional dos refugiados, criado pela Convenção de Genebra de 1951 e reformulado pelo Protocolo de Ratificação de $1967^{13}$, define como refugiado toda pessoa que “(...) devido a fundado temor de perseguição por motivos de raça, religião, nacionalidade, grupo social ou opiniões políticas, se encontra fora do país de sua nacionalidade e que não pode ou, em virtude desse temor, não quer valer-se da proteção desse país $(. . .)^{\prime \prime 14}$. Além dos refugiados estatutários ${ }^{15}$ e solicitantes de asilo, o ACNUR acumula mandato sobre deslocados internos (internal displaced persons, IDP) e apátridas (stateless) afetados por guerras e conflitos, somando cerca de 33,9 milhões de pessoas em todo o mundo. ${ }^{16} \mathrm{~A}$ aplicação de procedimentos

\footnotetext{
${ }^{11}$ MILANI, Carlos; ARTURI, Carlos S.; SOLINÍS, Germán. Democracia e Governança Mundial: que regulações para o século XXI?

${ }^{12}$ RIBEIRO, Gustavo Lins. El sistema mundial no-hegemónico y la globalización popular.

13 A Convenção Relativa ao Status de Refugiado, assinada em 1951, em Genebra, versa sobre a definição de refugiado e as responsabilidades assumidas por organizações e Estados de fornecer "proteção" a pessoas que deixaram seus países de origem para escapar a conflitos e perseguições no contexto da Segunda Guerra Mundial. Em 1967 foi assinado o Protocolo de Ratificação da Convenção de 1951, que, diante da eclosão de novos conflitos políticos armados em diferentes pontos da América Latina, África, Ásia e Europa Oriental, expandiu a definição de refugiado para abarcar essas novas realidades de refugiados.

${ }^{14}$ UNHCR. Convention and protocol relating to the status of refugees (tradução própria).

${ }^{15}$ Como são definidos os refugiados reconhecidos segundo a definição proposta na Convenção de Genebra.

${ }^{16}$ Números de 2010, retirados de UNHCR. UNHCR Global Trends 2010.
} 
e programas de reconhecimento e proteção de refugiados desenvolveu-se como uma tecnologia de governo não apenas populacional como igualmente territorial na medida em que atua em fronteiras nacionais e em campos de refugiados onde os mesmos permanecem por tempo indefinido ao mesmo tempo como exilados de sua comunidade de origem e não reconhecidos integralmente pelo país de destino. Análises comparativas sobre a relação de refugiados com o país de asilo sugerem que o deslocamento acaba se configurando, neste sentido, como uma primeira experiência de contato de determinadas populações com instituições estatais. ${ }^{17}$

O reconhecimento de refugiados de um determinado país é condicionado pela detecção de uma "crise humanitária" gerada por conflitos armados, violações sistemáticas de direitos humanos, instabilidades políticas, etc., que justifiquem alegações de "fundado temor de perseguição". A noção de crise humanitária, aqui, se refere não necessariamente ao estado de vulnerabilidade das pessoas afetadas, mas à insuficiência do próprio Estado como ator regulador dos fluxos migratórios. A noção de refugiado aparece, assim, quando há uma "crise" de reconhecimento do Estado tanto pelas pessoas deslocadas quanto pela comunidade internacional, que aciona mecanismos de cooperação e ajuda para a reconstrução de sua capacidade de atuação. A cooperação internacional constitui-se, assim, como uma rede pela qual circulam doações de recursos e compromissos políticos cujo equacionamento resulta em alinhamentos entre Estados doadores e Estados receptores de ajuda internacional. Estudos etnográficos sobre estes processos analisam as tensões e ambiguidades contidas nas performances discursivas que significam a ajuda internacional simultaneamente como um ato de solidariedade e humanitarismo, e como responsabilidade e interesse dos países mais ricos, caracterizando-os, assim, como circuitos de dádivas. ${ }^{18}$

$\mathrm{O}$ entendimento da indissociabilidade entre solidariedade e responsabilidade no campo da cooperação e ajuda internacionais nos permite problematizar como estas categorias são aplicadas por diferentes atores da política de proteção a refugiados. Não se trata de questionar o quanto a ajuda é movida por interesses instrumentais ou por sentimentos de dever moral, mas sim de explicitar as diferentes lógicas de apropriação, interpretação e ressignificação destas noções postas em prática através do posicionamento dos sujeitos neste circuito. Para tanto é necessário lançarmos um olhar sobre as modalidades de interação entre sujeitos situados em diferentes escalas operacionais e diferentes campos semânticos a partir dos quais interpretam os

${ }_{17}$ AGIER, Michel. Refugiados diante da nova ordem mundial, p. 204.

${ }^{18}$ SILVA, Kelly. A cooperação internacional como dádiva: algumas aproximações. 
princípios das políticas de proteção a refugiados, acessando as categorias de entendimento que engendram discursos e práticas agenciadoras das noções de solidariedade e responsabilidade.

\section{A cooperação internacional para a proteção de refugiados}

A reflexão sobre a cooperação sob o prisma da dádiva privilegia a análise das relações entre atores situados em determinados níveis hierárquicos, ainda que assimetricamente posicionados em termos de poder. A etnografia das performances de representantes de países doadores de recursos para a reconstrução do Timor Leste, por exemplo, enfatiza a dinâmica dos discursos e das relações inter-nacionais uma vez que são as doações e recomendações estatais, através de representantes e procuradores, que dinamizam o sistema de cooperação, seja através do agenciamento e influência exercidos em organismos internacionais, seja através de acordos e compromissos estabelecidos bilateralmente. ${ }^{19}$ Não obstante, é possível complexificar as relações de doação, recepção e retribuição de recursos através da análise de como a cooperação é operacionalizada para produzir os efeitos ritualmente objetivados por doadores e receptores em reuniões de alta cúpula. Ou seja, como é feita a "destinação" ou "uso" dos recursos acordada em ocasiões de reunião entre as partes da troca?

Além do eixo geopolítico, ou seja, das relações interestatais, a cooperação também se estabelece através de projetos nos quais são aplicados os recursos recebidos visando atender demandas específicas. No processo de construção ou reconstrução da capacidade estatal, os agentes da cooperação ocupam o papel de elaboradores e executores de políticas públicas, sejam estas voltadas para a criação e consolidação de instituições, seja para o atendimento de necessidades da população assistida por organismos internacionais. O uso dos recursos oriundos da cooperação internacional é, assim, delegado, através de contratos de consultoria e de prestação de serviços, a organizações e empresas selecionadas segundo critérios de objetividade e racionalidade técnica para a implementação de projetos em determinados setores de produção e serviços, cujo modus operandi opera como um meio de difusão de valores modernistas e de modelos hegemônicos de organização social derivados do pensamento internacional desenvolvimentista, gerando conflitos com as lógicas socioculturais particulares dos grupos assistidos. ${ }^{20}$

\footnotetext{
19 Ibidem, p. 147.

20 STIRRAT, Roderick L. Cultures of consultancy, p. 33. O autor sugere, inclusive, que o papel desempenhado por consultores de determinadas áreas de desenvolvimento seria uma forma de atualização do papel desempenhado, no passado, por funcionários públicos coloniais e missionários como agentes "civilizadores" de povos "primitivos".
} 
O programa de Reassentamento Solidário de refugiados na América Latina é implementado a partir de uma estrutura tripartite, dividida entre o ACNUR, os Comitês Nacionais para Refugiados (CONAREs) e organizações da sociedade civil. O tripartitismo é defendido e reafirmado pelas instituições em eventos periódicos realizados anualmente como uma fórmula de divisão do trabalho de assistência e proteção a refugiados. A exemplo do que ocorre com as relações entre doadores e receptores no campo da cooperação internacional, a dinâmica entre as instituições transnacionais, governamentais e os parceiros operacionais atuantes na implementação do programa de Reassentamento Solidário torna-se mais evidente nestes eventos na medida em que servem de cenário para que as instituições reafirmem compromissos e divulguem suas realizações. Por outro lado, tais eventos também permitem a identificação dos atores efetivamente implicados no processo de reassentamento de refugiados em cada lugar onde é implementado o programa, para além dos papéis assumidos segundo os modelos propostos.

A reflexão que proponho neste artigo, a respeito de como a noção de solidariedade é interpretada e ressignificada em diferentes escalas de implementação dos programas para refugiados, baseia-se em observações feitas em dois eventos de divulgação e debate sobre o programa de Reassentamento Solidário realizados em Porto Alegre. O primeiro foi o Encontro Regional sobre o Programa de Reassentamento Solidário, realizado em agosto de 2010, com a participação de representantes de países europeus e brasileiros participantes de programas de reassentamento, cuja programação incluiu uma coletiva de imprensa na qual foram divulgados números e informações atualizadas sobre o reassentamento de refugiados no Brasil; o segundo foi I Seminário de Proteção e Integração de Refugiados no Rio Grande do Sul, realizado em março de 2011, que reuniu o governador do estado, representantes de instituições relacionadas com imigrantes, tais como a Polícia Federal e o Ministério Público Estadual, e de municípios participantes do programa de Reassentamento Solidário. Ambos os eventos foram pautados pelas instituições que representam as posições da divisão tripartite do trabalho de implementação dos programas para refugiados: o ACNUR, o CONARE e a Associação Antônio Vieira (ASAV), organização jesuíta responsável pela implementação do Reassentamento Solidário no Rio Grande do Sul.

Os discursos dos representantes das instituições nestes eventos expressam o tripartitismo não apenas como uma relação estabelecida entre elas, mas também em termos de escalas de influência sobre o processo de reassentamento de refugiados que devem ser reiteradas publicamente diante de suas contrapartes contratuais. Nas duas ocasiões, o discurso do repre- 
sentante do ACNUR enfatizou aspectos que dizem respeito à posição internacional dos países participantes do programa de Reassentamento Solidário, em especial o fato de Brasil e Chile terem sido os primeiros países "emergentes" a receberem refugiados reassentados, demonstrando serem países "solidários"; o representante do CONARE foi o responsável pela divulgação das estatísticas brasileiras com relação ao tema do refúgio, apontando para o crescimento do número de refugiados reassentados no país, em especial no Rio Grande do Sul; a representante da ASAV trouxe informações sobre a situação dos refugiados reassentados nos municípios participantes do programa, classificados como "cidades solidárias", destacando o papel "sensível" da ASAV na detecção das necessidades de atendimento dos refugiados - em questões de saúde, moradia e educação, principalmente - e no apelo à solidariedade das populações dos municípios onde os refugiados agora vivem.

Mais do que o conteúdo das falas, propriamente dito, é relevante compreendermos o posicionamento das instituições em relação aos sujeitos do programa que estava sendo debatido nessas ocasiões, ou seja, os próprios refugiados reassentados. Ao ressaltar a posição internacional de Brasil e Chile como os primeiros países "emergentes" a reassentarem refugiados, o ACNUR reconhece sua participação na dinâmica da "solidariedade internacional", ou seja, na cooperação para a "repartição do peso" (burden sharing) representado pelas migrações forçadas, sobretudo para os países imediatamente vizinhos às regiões afetadas por "crises humanitárias" 21 . O reconhecimento do Brasil como um país solidário não se deve unicamente a sua disposição em receber refugiados reassentados, mas também pelo incremento das doações do país para o fundo do ACNUR na Organização das Nações Unidas $(\mathrm{ONU})^{22}$, cujos principais mantenedores são a Noruega e a União Europeia, bem como de sua participação nas operações militar no Haiti e de desenvolvimento no Timor Leste. Paralelamente, o Brasil exerce liderança dos países "emergentes" nos processos de negociação da Organização Mundial do Comércio (OMC), onde os principais adversários são a União Européia e os países ricos europeus, e pleiteia assento no Conselho de Segurança da

\footnotetext{
${ }^{21}$ A definição de solidariedade internacional vinculada ao conceito de burden sharing relacionada com proteção de refugiados foi debatida na 49a Sessão da Assembleia Geral da ONU. Ver UNHCR. [Annual theme] International solidarity and burden-sharing in all its aspects: national, regional and international responsibilities for refugees.

${ }^{22} \mathrm{O}$ analista de relações internacionais e consultor do ACNUR, Alexander Betts, assim define o papel do Brasil na assistência internacional a refugiados: "Além de receber refugiados colombianos e haitianos em seu território e fazer doações à causa, o Brasil tem crescido como ator político capaz de dialogar tanto com os países ricos que financiam os campos de refugiados, quanto com os pobres, que abrigam essas populações". ROSSETTI. Viagem sem fim: a maior crise de refugiados dos últimos 15 anos se arrasta sem perspectiva de saída próxima.
} 
ONU, do qual são membros permanentes somente China, Estados Unidos, França, Reino Unido e Rússia.

A participação dos países ditos "emergentes" nas dinâmicas da cooperação internacional para o desenvolvimento e em operações de caráter humanitário da ONU é criticada por analistas internacionais na medida em que se constituiria como uma espécie de "barganha" na qual os países ricos transfeririam parte do ônus de sua responsabilidade pelos processos de empobrecimento do sul global, tendo como contrapartida o reconhecimento dos emergentes como países desenvolvidos e com direito a participação nas instâncias decisórias da elite internacional. ${ }^{23}$ Minhas observações acerca das relações entre as instituições atuantes no sistema de proteção de refugiados, reconstituídas nestes encontros, privilegia a análise das formas de mediação deste processo. Ao acolher refugiados colombianos e palestinos que se encontravam em situações precárias, por exemplo, no Equador e na Jordânia, o Brasil não reparte o peso apenas com estes países, mas com o próprio sistema de proteção de refugiados, financiado majoritariamente por doações dos países mais ricos para os quais os refugiados seriam normalmente reassentados. Ao assumir a posição de doador de recursos e acolhedor de refugiados reassentados, o Brasil, através do CONARE e seus representantes, assume o compromisso de prestar solidariedade internacional, caracterizando-a também como uma obrigação contratual.

\section{Contextos de enunciação de valores}

O posicionamento do ACNUR em relação à cooperação para a proteção de refugiados é o de ordenador das relações internacionais. O reconhecimento do Brasil como um país solidário, correlacionado com seu status de economia "emergente", tem como contrapartida o cumprimento dos tratados e compromissos dos quais o país é signatário. A aplicação dos recursos e dos valores preconizados nos tratados internacionais é, no entanto, mediada pela rede de atores que operacionaliza o programa de Reassentamento Solidário. Ao afirmar seu papel "sensível" de reconhecer as necessidades imediatas dos refugiados reassentados conforme os municípios onde foram instalados, a ASAV se posiciona não apenas como um intermediário, responsável pela distribuição dos recursos, mas também como agente tradutor das idéias e valores ${ }^{24}$ em jogo na política de proteção internacional para o contexto das experiências cotidianas de refugiados e vice-versa. O papel "sensível" da ASAV no programa de Reassentamento Solidário refere-se, assim, a um

\footnotetext{
${ }^{23}$ BETTS. Development assistance and refugees: towards a north-south grand bargain?

${ }^{24}$ MERRY. Transnational human rights and local activism: mapping the middle, p. 42.
} 
processo de constante redefinição do sentido atribuído a determinados discursos de modo que sua tradução para as demandas dos beneficiários do Reassentamento Solidário engendre os propósitos preconizados pela agenda do ACNUR, ao mesmo tempo em que a tradução das necessidades experienciadas pelos refugiados para a linguagem da cooperação seja eficaz como reivindicação de direitos.

No evento de março de 2011, a fala da representante da ASAV foi precedida pela exibição de um vídeo intitulado "Parceiros da Solidariedade", que mostra depoimentos dos refugiados reassentados no Rio Grande do Sul gravados em suas próprias residências, e nos quais funcionários da ASAV aparecem sentados à mesa da cozinha ou no sofá da sala de estar, conversando sobre a saúde de algum membro da família, sobre o emprego de cada um, etc. O vídeo, assim como a fala da representante, expressavam uma familiaridade com os refugiados que credencia a ASAV como mediadora do programa de Reassentamento Solidário junto aos refugiados, bem como das demandas destes junto ao ACNUR e ao CONARE. Além disso, a ASAV também atua como mediadora entre a política global de cooperação para a proteção de refugiados e as práticas localizadas de assistência social destinadas a refugiados através da celebração de convênios com governos municipais para a criação de mecanismos que facilitem o acesso dos refugiados a serviços públicos e emprego, tendo como contrapartida o reconhecimento dos municípios cooperantes como "cidades solidárias". Embora a solidariedade esteja, aqui, mais uma vez vinculada a um compromisso assumido, e portanto se configure oficialmente como uma responsabilidade, a eficácia política dessa certificação depende, também, do agenciamento da participação social no processo de acolhida dos refugiados.

A coletiva de imprensa de 2010 foi aberta pelo depoimento do representante do governo da Noruega, que um dia antes havia visitado a cidade de Serafina Correa, na serra gaúcha, onde haviam sido reassentados dezesseis refugiados colombianos, desde 2005. De acordo com ele, os refugiados reassentados em Serafina Correa poderiam ser considerados integrados, pois todos tinham emprego, diferentemente da Noruega, onde refugiados permaneceriam por mais tempo ligados aos benefícios do sistema de bem-estar social oferecido pelo Estado. Já no evento de 2011 o vice-prefeito do município de Venâncio Aires apresentou um depoimento sobre a experiência de acolhimento de cinco famílias (treze pessoas) de refugiados palestinos no município, ressaltando a presença prévia de uma colônia de palestinos no município que teria facilitado a adaptação local dos refugiados. Além disso, salientou o papel da imigração na formação social do município, 
majoritariamente povoado por alemães e descendentes de alemães desde o início do século XX, como um fator gerador de empatia entre a população local e os refugiados, facilitando a obtenção de emprego e a criação de redes de apoio. O depoimento do vice-prefeito de Venâncio Aires neste evento também marcou a indicação do município para a certificação como "Cidade Solidária". Os relatos a respeito da "integração" de refugiados em municípios do interior do Rio Grande do Sul redimensionam, assim, o sentido da noção de solidariedade para as relações interpessoais entre refugiados e a sociedade de acolhida.

Os depoimentos de pessoas externas à estrutura tripartite de cooperação para a proteção internacional de refugiados atestam a atuação fundamentalmente "local" da ASAV, em contraste com o campo transnacional de atuação do ACNUR, traduzidas de uma escala à outra por meio da transversalidade do sentido da noção de solidariedade ligada ora às relações internacionais ora às relações interpessoais. Nesse sentido, tradução não significa uma transição no sentido do mais global para o mais local, mas dos contextos a partir dos quais os atores constroem seus posicionamentos na política analisada. A própria noção de contexto auxilia a compreensão deste processo na medida em que é agenciada para elencar fatores com poder condicionante ou determinante sobre eventos observados, bem como sobre o olhar do observador. Resulta daí uma definição de contexto como uma combinação de fatores que colocam os sujeitos da pesquisa em um determinado contexto de enunciação, no qual determinadas categorias fazem mais sentido do que outras. ${ }^{25}$

A diferença entre as concepções de solidariedade internacional característica do discurso do ACNUR e de solidariedade atrelada às redes de ajuda e inserção social de famílias de refugiados não corresponde unicamente a uma diferença de abrangência ou alcance geopolítico do campo de ação dos atores que participam da proteção internacional de refugiados. Ao enfatizar o papel "solidário" dos países "emergentes", o ACNUR sumariza a posição internacional destes países no campo dos tratados e convenções internacionais que regulam, segundo a lógica do direito internacional público, a relação entre Estados nacionais em relação a questões específicas. O mandato do ACNUR não diz respeito, assim, às pessoas refugiadas, mas ao monitoramento das políticas estatais em relação a refugiados e ao repasse de recursos oriundos de doações internacionais para que as premissas das convenções internacionais sejam internalizadas e difundidas. A abordagem

${ }^{25}$ ABÉLÈS, Marc. O racionalismo posto à prova da análise; BENSA, Alban. Da micro-história a uma antropologia crítica. 
"global" do ACNUR em relação a refugiados reconhece as situações "locais" socioculturalmente variadas ao redor do mundo, porém informada por categorias e valores do direito internacional e das organizações interestatais. Da mesma forma, a perspectiva "local" trazida pelos depoimentos a respeito da situação de refugiados nas "Cidades Solidárias" reconhece a abrangência e relevância dos refugiados como um tema "global". No caso analisado, porém, o fenômeno das migrações forçadas é interpretado a partir das experiências de assentamento de imigrantes europeus no início do século XX no Brasil.

A tradução da política de proteção a refugiados da esfera global para a esfera local é viabilizada pela noção de solidariedade na medida em que cada ator consegue se posicionar como "solidário" a partir de experiências e categorias de entendimento próprias, inserindo-se no circuito não somente de acolhida de refugiados, mas também de recursos e reconhecimentos oficiais desta solidariedade. A exemplo do que as discussões sobre a dádiva como espaço de estabelecimento de relações e alianças sugerem, podemos observar no processo de implementação do Reassentamento Solidário também um espaço de intercâmbio de valores associados às categorias de solidariedade e responsabilidade sintetizados nas idéias de cooperação e ajuda, tanto internacionais quanto locais, que evidenciam a construção social das fronteiras entre a solidariedade como uma responsabilidade contratual ou como uma retribuição moral.

\section{Considerações finais}

A manifestação de refugiados palestinos em 2008 em Brasília evidenciou um conflito entre interpretações e sentidos atribuídos às ideias de responsabilidade e solidariedade no campo da cooperação. Ao entrarem no programa de Reassentamento Solidário os sujeitos refugiados assumem uma posição identificada, ao mesmo tempo, em função dos direitos que lhes cabem e do poder sobre eles exercidos. Pensados como produto de "crises humanitárias" resultantes da incapacidade dos Estados nacionais de regular os fluxos migratórios, os refugiados tornam-se sujeitos a serem governados pela comunidade internacional, que também é responsável pela restauração das capacidades estatais de realizá-lo. Do ponto de vista jurídico, a responsabilidade do ACNUR é, assim, limitada à tarefa de colocar refugiados sob governo estatal. Ao conceder asilo a refugiados, o Estado que os recebe oferece as mesmas condições de proteção e desenvolvimento oferecidos à população nacional. Ao celebrar convênios com países "emergentes" para o reassentamento de refugiados o ACNUR automaticamente os certifica como suficientemente desenvolvidos para oferecer condições mínimas de 
proteção, e suficientemente "solidários" para dividirem o peso representado pelos refugiados.

Ao reivindicar ao ACNUR melhorias nos serviços de assistência social, os refugiados palestinos reassentados no Brasil posicionavam-se sob o governo humanitário do ACNUR, e não sob o governo estatal do Brasil, ou seja, como responsabilidade do ACNUR. A ação dos refugiados palestinos aponta, assim, para uma dimensão fundamental a ser considerada em estudos sobre as políticas de refúgio: os critérios utilizados para se considerar refugiados "assentados" ou "integrados" na sociedade de acolhida. Pela lógica da cooperação internacional, a integração do refugiado corresponde ao processo de formalização de seu status jurídico no país onde é reassentado. A responsabilidade do ACNUR termina, assim, onde começa a responsabilidade do Estado. O modelo de divisão tripartite do trabalho de assistência a refugiados representa, nesse sentido, a ambiguidade entre tornar a realidade "local" dos refugiados inteligível para atores situados em um contexto de enunciação de valores "globais", mas também de delegação e distanciamento entre as esferas do planejamento e elaboração de recomendações, por um lado, e da execução e assistência prestada aos sujeitos destas políticas, por outro.

Por fim, a análise da circulação da ideia de solidariedade no campo da cooperação para a proteção internacional de refugiados aponta para uma ampliação da noção de contrato, relacionando-a também com a reciprocidade e o reconhecimento sociais. Ao apresentar a acolhida e inserção social de refugiados nas cidades do interior do Rio Grande do Sul como uma retribuição pela recepção de imigrantes europeus no passado, o viceprefeito de Venâncio Aires formaliza uma noção difusa de contrato existente entre descendentes de imigrantes e o Estado brasileiro, sobretudo no que diz respeito à concessão de terras para cultivo que caracterizou os povoamentos por imigrantes, remetendo a uma retórica da gratidão, o que vai além da troca estabelecida em convênio que resulta em seu reconhecimento como "Cidade Solidária". Da mesma forma, a relação entre o Brasil e o ACNUR é celebrada formalmente como um contrato de divisão de responsabilidades ampliada pelo agenciamento político, no cenário internacional, de seu reconhecimento como país "emergente" e "solidário".

\section{Bibliografia}

ABÉLÈS, Marc. O racionalismo posto à prova da análise. In REVEL, Jacques. Jogos de escalas: a experiência da microanálise. Rio de Janeiro: Editora Fundação Getúlio Vargas, 1998, p. 103-120. 
AGIER, Michel. Refugiados diante da nova ordem mundial. Tempo Social, v. 18, n. 2, 2006, p. 197-215.

APTHORPE, Raymond. Writing development policy and policy analysis plain or clear: on language, genre and power. In SHORE, Chris; WRIGHT, Susan (Eds.). Anthropology of Policy: critical perspectives on governance and power. New York: Routledge, 2005.

BENSA, Alban. Da micro-história a uma antropologia crítica. In REVEL, Jacques. Jogos de escalas: a experiência da microanálise. Rio de Janeiro: Editora Fundação Getúlio Vargas, 1998, p. 39-76.

BETTS, Alexander. Development assistance and refugees: towards a north-south grand bargain?. Forced Migration Policy Briefing 2, 2009.

CHANIAL, Phillipe. Generosité, réciprocité, pouvoir et violence: esquisse d'une grammaire des relations humaines en clé de don. Revue du MAUSS, v. 32, n. 2, 2008, p. 97-123.

CHAVAGNEUX, Christian. Une maîtrise politique de la mondialisation economique. Revue du MAUSS v. 20, n. 2, 2002, p. 54-64.

DURKHEIM, Émile. Da divisão social do trabalho. São Paulo: Martins Fontes, 1995 [1893].

GODELIER, Maurice. O enigma do dom. Rio de Janeiro: Civilização Brasileira, 2001.

HART, Keith. Marcel Mauss: In Pursuit of the Whole. A Review Essay. Comparative Studies in Society and History, v. 49, n. 2, 2007, p. 1-13.

LÉVI-STRAUSS, Claude. Introdução à obra de Marcel Mauss. In MAUSS, Marcel. Sociologia e antropologia. São Paulo: Cosac \& Naify, 2003[1950], p. 11-46.

MAUSS, Marcel. Sociologia e antropologia. São Paulo: Cosac \& Naify, 2003[1950].

MERRY, Sally. Transnational human rights and local activism: mapping the middle. American Anthropologist, v. 108, n. 1, 2006, p. 38-51.

MILANI, Carlos; ARTURI, Carlos; SOLINÍS, Germán (orgs.). Democracia e governança mundial: que regulações para o século XXI? Porto Alegre: Editora da UFRGS/ UNESCO, 2002.

RIBEIRO, Gustavo Lins. El sistema mundial no-hegemónico y la globalización popular. Série Antropologia, n. 410, 2007.

- Diversidade cultural enquanto discurso global. Desigualdade \& Diversidade, n. 2, 2008, p. 199-233.

SILVA, Kelly. A cooperação internacional como dádiva: algumas aproximações. Mana, v. 14, n. 1, 2008, p. 141-171.

STIRRAT, Roderick L. Cultures of consultancy. Critique of Anthropology, v. 20, n. 1, 2000, p. 31-46.

TAROT, Camille. L'économique et le social, ou l'utopie. In IDEM. Sociologie et anthropologie de Marcel Mauss. Paris: La Découverte, 2003, p. 66-79.

ZELIZER, Viviana. Intimité et economie. Terrain, n. 45, 2005, p. 13-28. 
Noções de solidariedade e responsabilidade no campo da cooperação internacional para os refugiados

\section{Documentos oficiais e mídia}

Refugiados palestinos protestam em Brasília para deixar o país. Estadão.com. br, 23 de junho de 2008. Disponível em: <www.estadao.com.br/noticias/ internacional, refugiados-palestinos-protestam-em-brasilia-para-deixar-opais, 194343,0.htm>. Acesso em: 08.08.2011.

ROSSETTI, Carolina. "Viagem sem fim: a maior crise de refugiados dos últimos 15 anos se arrasta sem perspectiva de saída próxima". Caderno Aliás, a semana revista, O Estado de São Paulo, 28 de junho de 2011.

UNHCR, United Nations High Commissioner for Refugees. UNHCR Global Trends 2010, Geneva: UNHCR, 2011. Disponível em: <www.unhcr.org/refworld/ docid/4e01b00e2.html>. Acesso em: 08.08.2011.

. "[Annual Theme] International Solidarity and Burden-Sharing in all its

Aspects: National, Regional and International Responsibilities for Refugees", A/ AC.96/904, 7 de setembro de 1998. Disponível em: <www.unhcr.org/refworld/ docid/4a54bc2fo.html>. Acesso em: 08.08.2011.

. "Convention and protocol relating to the status of refugees". Basic documents, setembro de 2007. Disponível em: <www.unhcr.org/3b66c2aa10. html>. Acesso em: 08.08.2011.

\section{Abstract}

Notions of solidarity and responsibility in the field of international cooperation on refugee protection

Following events related to the Solidarity Resettlement program for refugees in Brazil, the article looks to analyze how the principles of solidarity and responsibility elaborated in the scope of international agreements are interpreted and re-signified by social actors situated in different scales of influence and participation in the implementation of refugee protection and social policies.

Keywords: Solidarity; Responsibility; Refugees; Policy; Cooperation.

Recebido para publicação em 20/07/2012.

Aceito para publicação em 27/11/2012.

Received for publication on July, 20 th, 2012.

Accepted for publication on November, $27^{\text {th }}, 2012$. 